\title{
The effect of myeloperoxidase isoforms on biophysical properties
} 2 of red blood cells

\author{
Ekaterina V. Shamova ${ }^{1}$ Irina V. Gorudko ${ }^{1}$ - Daria V. Grigorieva ${ }^{1}$ - Alexey V. Sokolov ${ }^{2,3,4}$ - Anatoli U. Kokhan ${ }^{1}$. \\ Galina B. Melnikova ${ }^{5}$ - Nikolai A. Yafremau ${ }^{6}$. Sergey A. Gusev ${ }^{4}$. Anastasia N. Sveshnikova ${ }^{7}$. Vadim B. Vasilyev ${ }^{2,3}$. \\ Sergey N. Cherenkevich ${ }^{1}$. Oleg M. Panasenko ${ }^{4,8}$
}

Received: 22 March 2019 / Accepted: 8 November 2019

๑) Springer Science+Business Media, LLC, part of Springer Nature 2019

\begin{abstract}
Myeloperoxidase (MPO), an oxidant-producing enzyme, stored in azurophilic granules of neutrophils has been recently shown to influence red blood cell (RBC) deformability leading to abnormalities in blood microcirculation. Native MPO is a homodimer, consisting of two identical protomers (monomeric MPO) connected by a single disulfide bond but in inflammatory foci as a result of disulfide cleavage monomeric MPO (hemi-MPO) can also be produced. This study investigated if two MPO isoforms have distinct effects on biophysical properties of RBCs. We have found that hemi-MPO, as well as the dimeric form, bind to the glycophorins $\mathrm{A} / \mathrm{B}$ and band three protein on RBC's plasma membrane, that lead to reduced cell resistance to osmotic and acidic hemolysis, reduction in cell elasticity, significant changes in cell volume, morphology, and the conductance of RBC plasma membrane ion channels. Furthermore, we have shown for the first time that both dimeric and hemi-MPO lead to phosphatidylserine (PS) exposure on the outer leaflet of RBC membrane. However, the effects of hemi-MPO on the structural and functional properties of RBCs were lower compared to those of dimeric MPO. These findings suggest that the ability of MPO protein to influence RBC's biophysical properties depends on its conformation (dimeric or monomeric isoform). It is intriguing to speculate that hemi-MPO appearance in blood during inflammation can serve as a regulatory mechanism addressed to reduce abnormalities on RBC response, induced by dimeric MPO.
\end{abstract}

Keywords Monomeric myeloperoxidase $\cdot$ Dimeric myeloperoxidase $\cdot$ Inflammation $\cdot$ RBC $\cdot$ Phosphatidylserine

Electronic supplementary material The online version of this article (https://doi.org/10.1007/s11010-019-03654-0) contains supplementary material, which is available to authorized users.

$\triangle$ Ekaterina V. Shamova shamova@tut.by

1 Belarusian State University, Minsk, Belarus

2 FSBSI "Institute of Experimental Medicine", St. Petersburg, Russia

3 Saint-Petersburg State University, St. Petersburg, Russia

$4 \quad$ FSBI "Federal Research and Clinical Center of PhysicalChemical Medicine" FMBA, Moscow, Russia

5 A.V. Luikov Heat and Mass Transfer Institute of the National Academy of Sciences of Belarus, Minsk, Belarus

6 State Institution «N.N. Alexandrov Republican Scientific and Practical Center of Oncology and Medical Radiology», Minsk, Belarus

7 Lomonosov Moscow State University, Moscow, Russia

8 Pirogov Russian National Research Medical University, Moscow, Russia

\section{Introduction}

Myeloperoxidase (MPO) is a cationic protein, which is most abundantly expressed in azurophilic granules of neutrophils ( $2-5 \%$ of the total cellular protein). It is a heme-containing glycosylated oxidoreductase, which in addition to its peroxidase activity, catalyzes the production of (pseudo)hypohalous acids (halogenating activity), mainly hypochlorous $(\mathrm{HOCl})$, hypothiocyanous (HOSCN) and hypobromous (HOBr) acids [1-4]. Being strong oxidants and halogenating agents, hypohalous acids interact with many biologically important molecules: nucleic acids, proteins, lipids, carbohydrates, etc. [5, 6]. Due to this, MPO has a bactericidal function. However, excessive production of reactive halogen-containing compounds (reactive halogen species) can lead to host cell and tissue damage, initiating the development of oxidative/halogenative stress and triggering a number of diseases associated with inflammation [6-8].

\begin{tabular}{|l|l|l|l|l|}
\hline Journal : Large 11010 & Article No : 3654 & Pages : 12 & MS Code : 3654 & Dispatch : 15-11-2019 \\
\hline
\end{tabular}


MPO can also regulate the function of immune and nonimmune cells via its nonenzymatic effects. MPO binding with the cell surface of platelets [9, 10], neutrophils [11, 12], and erythrocytes $[13,14]$ are able to activate the processes of intracellular signaling, leading to changes in the structural and functional properties of these cells.

Native MPO, released into the extracellular space as a result of neutrophil degranulation, is a homodimer, consisting of two identical protomers connected by a single disulfide bond, each containing light, heavy chains and heme [15]. Synthesis of dimeric MPO from monomeric ones is carried out at the stage of promyelocyte differentiation into granulocytes, as a result of which a dimeric glycosylated heme-containing MPO is formed [16, 17].

Under in vitro conditions, the monomeric form of MPO, termed hemi-myeloperoxidase (hemi-MPO), can be easily formed by a cleavage of disulfide bond by reduction and alkylation, linking two identical protomers in native MPO [18]. Recently, we have shown that monomeric MPO can be formed in vitro by $\mathrm{HOCl}$-induced disulfide bond oxidation [19]. These results suggest the possibility of hemi-MPO formation in inflammatory foci, where the generation of reactive halogen species is increased and various redox reactions are initiated. Indeed, recently we have shown the presence of hemi-MPO in the plasma of patients with marked inflammation [20]. Under in vivo conditions, the appearance of hemiMPO is also possible as a result of incomplete processing to the mature enzyme $[16,17]$.

One of current interest is the question of whether the functional properties of two MPO isoforms are different or similar and whether hemi-MPO, as well as the dimeric form, are able to bind to cell surface and regulate intracellular signaling processes.

Recently, we have shown that hemi-MPO induced cytosolic $\mathrm{Ca}^{2+}$-rise, as well as lysozyme and elastase degranulation in human neutrophils, but these effects were much weaker than observed in the case of dimeric MPO [20]. It should be noted that hemi-MPO has the same as dimeric MPO peroxidase and chlorinating activity and retains its bactericidal ability [16, 17, 21].

In this work, we carried out a comparative analysis of the hemi-MPO (obtained by disulfide bond reduction in dimeric MPO) and dimeric MPO effects on the structural and functional properties of red blood cells (RBCs). We have shown that hemi-MPO, as well as the dimeric form, bind to the glycophorins $\mathrm{A} / \mathrm{B}$ and band 3 protein on RBC's plasma membrane, that led to changes in transmembrane potential, RBC morphology, reduced RBC deformability and reduced resistance to hemolysis. It was for the first time demonstrated that both dimeric and hemi-MPO induced the exposure of phosphatidylserine (PS) to the outer surface of the RBC membrane. However, all observed effects of hemiMPO were significantly weaker than in the case of dimeric
MPO. According to these data, it is intriguing to speculate that decomposition of native MPO into monomers in vivo may serve as a regulatory mechanism aimed to correct RBC function under inflammatory conditions.

\section{Materials and methods}

\section{Chemicals}

4-Aminobenzoic acid hydrazide (4-ABH), sodium citrate, 4-chloro-1-naphthol, $\mathrm{H}_{2} \mathrm{O}_{2}$, HEPES, ethylene glycolbis(2-aminoethylether)- $N, N, N^{\prime}, N^{\prime}$-tetraacetic acid (EGTA), phorbol 12-myristate 13-acetate (PMA), ionomycin were purchased from Sigma-Aldrich (St. Louis, USA). Sodium L-aspartate was from Alfa Aesar (Ward Hill, USA). Highaffinity rat and rabbit polyclonal antibodies against human MPO were prepared as described previously [22]. HL-60, cell culture medium (RPMI-1640), and fetal calf serum (FCS) were purchased from BioloT Ltd (Saint-Petersburg, Russia).

\section{Isolation of dimeric MPO}

The HL-60 cell line (promyelocytic leukemia) was used as a source of dimeric MPO. MPO isolated from HL-60 was identical to MPO isolated from human neutrophils by size exclusion chromatography, SDS-PAGE, Western blotting, $\mathrm{N}$-terminal sequence analysis and have the same peroxidase and chlorinating activities [23]. Cells were cultivated at $37{ }^{\circ} \mathrm{C}$ and $100 \%$ humidity in RPMI- 1640 medium, containing 10\% FCS, $2 \mathrm{mM}$ glutamine and $25 \mathrm{mM}$ HEPES buffer ( $\mathrm{pH} 7.4)$, in roller bottles for suspension culture. Once a week, cells were sedimented by centrifugation at $1500 \mathrm{~g}$, the pellet was resuspended in a minimum volume of fresh medium, and $1 / 5$ of the volume of this cell suspension was transferred to a roller bottle containing fresh medium, while the remaining cells were washed three times with phosphatebuffered saline (PBS, $10 \mathrm{mM} \mathrm{Na} \mathrm{HPO}_{4} / \mathrm{KH}_{2} \mathrm{PO}_{4}, 137 \mathrm{mM}$ $\mathrm{NaCl}, 2.7 \mathrm{mM} \mathrm{KCl}, \mathrm{pH}$ 7.4), resuspended in 2 volumes of $100 \mathrm{mM}$ Na-acetate buffer (pH 4.7) and frozen. Dimeric MPO was isolated from the extract of thawed HL-60 cells lysed by ultrasound $(44 \mathrm{kHz})$ and purified by affinity chromatography on heparin-Sepharose, hydrophobic chromatography on phenyl-Sepharose, and gel filtration on Sephacryl S-200 HR [24]. Using this method, it is possible to isolate a homogeneous preparation of dimeric MPO with a high specific activity and a purity index $\left(A_{430} / A_{280}\right)$ greater than 0.85 .

\section{Preparation of hemi-MPO [25]}

The hemi form of MPO was prepared by treating dimeric MPO $(145 \mu \mathrm{M})$ with 2-mercaptoethanol (1:4 molar ratio of
110 
MPO to 2-mercaptoethanol) for $30 \mathrm{~min}$ at $37^{\circ} \mathrm{C}$ in $100 \mathrm{mM}$ Na-carbonate buffer, pH 9.4, as described elsewhere [18, 25]. SH-groups were then blocked with iodoacetamide for 30 min at $4{ }^{\circ} \mathrm{C}$ (1:20 molar ratio of MPO to iodoacetamide). The resulting protein solution was concentrated in VivaSpin 20 ultrafiltration units (Sartorius, Germany) with a molecular weight cut-off of $30 \mathrm{kDa}$, with the buffer being exchanged for $100 \mathrm{mM}$ Na-acetate buffer (pH 5.5). Traces of dimeric MPO were separated from hemi-MPO by gel filtration on a Sephacryl S-200 HR column $(114 \times 1.5 \mathrm{~cm})$ equilibrated with $100 \mathrm{mM} \mathrm{Na}$-acetate buffer (pH 5.5). SDS-PAGE in non-reducing conditions showed a complete absence of the dimeric form in hemi-MPO preparation. It was shown that there were no differences in peroxidase, chlorinating and bactericidal activity between hemi-MPO and dimeric MPO [25]. Concentration of dimeric and hemi-MPO was determined spectrophotometrically using an extinction coefficient of $112,000 \mathrm{M}^{-1} \cdot \mathrm{cm}^{-1}$ per heme of MPO.

\section{Isolation of RBCs}

Washed RBCs were obtained after two centrifugation cycles at $400 \mathrm{~g}$ for $5 \mathrm{~min}$ of capillary blood $(100 \mu \mathrm{l})$ in $10 \mathrm{ml}$ of PBS or venous blood collected in tubes containing $3.8 \%$ $(\mathrm{w} / \mathrm{v})$ sodium citrate as anticoagulant at a ratio of 9:1 and stored in PBS, containing $10 \mathrm{mM}$ D-glucose at $4{ }^{\circ} \mathrm{C}$. Washed RBCs from capillary blood ( $1 \%$ hematocrit, unless otherwise indicated) were used for AFM, hemolysis, patch-clamp and flow cytometry assays whereas washed RBC from venous blood were used to prepare RBC ghosts (RBCGs) by hypoosmotic hemolysis. Venous blood samples were obtained from healthy donors at Federal State Budgetary Scientific Institution "Institute of Experimental Medicine". All blood donors were volunteers and gave informed consent.

\section{RBCGs preparation}

Washed RBCs were mixed with cold hemolysis buffer (10 mM Tris- $\mathrm{HCl}, 1 \mathrm{mM}$ EDTA, $\mathrm{pH} \mathrm{7.6,4}{ }^{\circ} \mathrm{C}$ ) at a 1:20 ratio by volume and incubated at $4{ }^{\circ} \mathrm{C}$ for $5 \mathrm{~min}$. Then, the sample was centrifuged twice at $30,000 \times g\left(30 \mathrm{~min}, 4{ }^{\circ} \mathrm{C}\right)$ and the RBCG pellet was resuspended with cold hemolysis buffer: by 10 volumes (first centrifugation) and by 3 volumes (second centrifugation). The final RBCG suspension was used for downstream procedures.

\section{Detection of MPO-binding proteins using ligand western blot assay}

RBCGs were lysed in SDS-Tris sample buffer $(125 \mathrm{mM}$ Tris- $\mathrm{HCl}, \mathrm{pH}$ 6.8, 2\% SDS, 0.1\% 2-mercaptoethanol, $0.001 \%$ bromphenol blue, and $50 \%$ glycerol) at a ratio $1: 5$ by volume, and $100 \mu \mathrm{g}$ of total protein was loaded per well of polyacrylamide gel [26]. Using a semi-dry method [27] the separated proteins were transferred on nitrocellulose membranes and the blocking procedure was performed using a blocking solution BSA-T (1\% BSA amd $0.05 \%$ Tween 20 in PBS). To detect RBC proteins, which bind with MPO isoforms, the membranes were incubated for $30 \mathrm{~min}$ with hemi- or dimeric MPO in BSA-T solution, followed by exposure for $1 \mathrm{~h}$ to HRP-labeled rabbit anti-human MPO antibody. Each step was accompanied by washing of the membranes three times with BSA-T solution for at least 5 min per washing step. The peroxidase activity was visualized using 4-chloro-1-naphthol plus $\mathrm{H}_{2} \mathrm{O}_{2}$ system. In the absence of HRP-labeled antibody, basal MPO peroxidase activity was not manifested. There were no difference between MPO and hemi-MPO in binding to the HRP-labeled antibody against MPO as was shown in control dot-blotting experiments. The identity of MPO-binding protein bands on SDS-PAGE gels was confirmed by mass spectrometry after in situ tryptic digestion [28].

\section{Hemolysis detection}

A suspension of washed RBCs $(30 \mu \mathrm{l})$ treated or not with monomeric/dimeric MPO was added to $60 \mathrm{mM} \mathrm{NaCl}$ solution $(300 \mu \mathrm{l})$ to induce hypotonic hemolysis or to phosphate-citrate buffer containing $155 \mathrm{mM} \mathrm{NaCl}$ and $4.1 \mathrm{mM} \mathrm{Na} \mathrm{HPO}_{4} / 7.9 \mathrm{mM}$ citric acid $(300 \mu \mathrm{l})$ to induce acidic hemolysis. The process of hemolysis was recorded as changes in light transmission at $670 \mathrm{~nm}$ and $37{ }^{\circ} \mathrm{C}$ of constantly stirred cell suspensions using analyzer AP2110 (SOLAR, Minsk, Belarus). To quantify the hemolysis process the following parameters were used: $G$, maximal extent of hemolysis, i.e., the maximal level of light transmission of cell suspension at the plateau, and $t_{50}$, the time point when the change in light transmission has reached its half-maximal value.

\section{Atomic force microscopy (AFM) measurements}

RBCs were treated with monomeric/dimeric MPO for $10 \mathrm{~min}$ at room temperature and then fixed in $1.5 \%$ glutaraldehyde for $30 \mathrm{~min}$. Fixed RBCs were washed by fourstep centrifugation at $400 \mathrm{~g}$ for $3 \mathrm{~min}$ and the RBC pellet was resuspended twice in PBS and twice in distilled water. Washed RBCs were placed on a glass slide and air-dried for several hours. All steps were performed at room temperature.

The images of RBC's surface membrane were obtained using a NT-206 microscope (MicroTestMachines, Minsk, Belarus) working in the contact mode using the software of the microscope. Standart cantilevers NSC 11A («MikroMasch » Co, Estonia) with a spring constant of $3 \mathrm{~N} / \mathrm{m}$ were used. Tip radii were checked by using a standard TGT01 silicon grating from NT-MDT (Moscow, Russia) and were
204

\begin{tabular}{|l|l|l|l|l|}
\hline Journal : Large 11010 & Article No : 3654 & Pages : 12 & MS Code : 3654 & Dispatch : 15-11-2019 \\
\hline
\end{tabular}


$10 \mathrm{~nm}$ for topography visualization and $60 \mathrm{~nm}$ for cell stiffness determination. Surface profiles were obtained using scan sizes of $14 \times 14 \mathrm{~mm}$ at a scan rate of $3 \mathrm{~Hz}$. The resulting image (topographic image) was recorded as a surface height distribution $Z(X, Y)$. For each scanned cell, the height $H$ (maximum cell height), the concave depth $h$ (minimum height of the cell), the diameter of $\mathrm{RBC}-d$ and the relative concave depth $-k$ were determined: $k=(H-h) / h \cdot 100 \%$.

The force spectroscopy regime was used to determine local elastic properties of RBCs. At least three force curves from the peripheral part of the randomly selected cells (7-10 cells) for each treatment were recorded. The cell Young's modulus was calculated as described earlier [29] using Hertz model and used as a measure of RBC stiffness. The indentation depth was $15 \mathrm{~nm}$ to avoid the influence of a rigid substrate on the magnitude of the estimating Young's modulus [30].

\section{Light microscopy}

To observe changes in RBC morphology, induced by MPO isoforms, RBCs were suspended in PBS, pH 7.4, with $1 \mathrm{mM}$ $\mathrm{CaCl}_{2}$, placed in a Petri dish and transferred to an optical microscope for analysis. The transmitted light images of the RBCs were recorded before (control) and after MPO addition to cell suspension at time intervals of $15-60 \mathrm{~s}$ for 15 min using an optical microscope Olympus BX51WI (Tokyo, Japan), LUMPlan objective $(40 \times / 0.80)$ and digital camera OSCAR 45 (Taiwan). Quantitative analysis was performed using the analyzer Meco-Hemo (Mecos, Russia) counting approximately 500 cells per each image.

\section{Measurement of RBC membrane potential by patch-clamp technique}

Washed RBCs $(5 \mu \mathrm{l})$ were carefully placed in the bottom of a Petri dish, filled with $5 \mathrm{ml}$ of external buffer solution $(145 \mathrm{mM} \mathrm{NaCl}, 10 \mathrm{mM}$ HEPES, $10 \mathrm{mM}$ D-glucose, $5 \mathrm{mM} \mathrm{KCl}, 1 \mathrm{mM} \mathrm{MgCl}_{2}, 1 \mathrm{mM} \mathrm{CaCl} 2, \mathrm{pH} 7.4$, osmolarity $290 \mathrm{mOsm}$ ). Patch pipettes with tip resistance 10-20 M $\Omega$ were prepared from borosilicate glass before each experiment using a puller Sutter P-97 (HEKA Elektronik, GmbH) and filled with internal buffer solution $(5 \mathrm{mM} \mathrm{NaCl}, 10 \mathrm{mM}$ HEPES, $145 \mathrm{mM} \mathrm{KCl}, 1 \mathrm{mM} \mathrm{MgCl} 2,0.3 \mathrm{mM} \mathrm{CaCl}_{2}, 3 \mathrm{mM}$ EGTA, pH 7.2, osmolarity $280 \mathrm{mOsm}$ ). A micromanipulator MP-225 (Sutter Instrument) was used to bring the patch pipette close to a single RBC and then a small negative pressure was applied to the pipette, leading to giga-seal formation (3-10 G $\Omega$ ). Patch-clamp recordings of membrane potential were carried out in cell-attach configuration in current-clamp mode using an amplifier HEKA EPC 8 (HEKA Elektronik, $\mathrm{GmbH}$ ), filtered at $1 \mathrm{kHz}$. When the successful cell-attached configuration was achieved and membrane potential reached the constant values $(15-20 \mathrm{mV})$, dimeric or hemi-MPO was added to bath solution and changes in membrane potential were recorded.

\section{Flow cytometry}

To probe PS exposure, washed RBCs were suspended at $0.015 \%$ hematocrit in PBS, $\mathrm{pH} 7.4$, with $2 \mathrm{mM} \mathrm{CaCl}_{2}$, treated with monomeric/dimeric MPO or ionomycin/PMA for $15 \mathrm{~min}$ at room temperature, stained with Annexin V-Alexa Fluor $647(100 \mu \mathrm{g} / \mathrm{ml})$ under protection of light for $5 \mathrm{~min}$ at room temperature und used immediately for flow cytometry assay. PS exposure was measured in the FL-6 channel $(660 \mathrm{~nm})$ excited at $638 \mathrm{~nm}$. 10,000 cells were measured per each sample.

To measure intracellular $\mathrm{Ca}^{2+}, \mathrm{RBCs}$ were incubated with $3.5 \mu \mathrm{M}$ Fluor-3/AM in PBS for $60 \mathrm{~min}$ at $37^{\circ} \mathrm{C}$ in the dark, followed by centrifugation $(300 \mathrm{~g}, 7 \mathrm{~min})$ and subsequent washing in PBS three times. Fluor-3-loaded RBCs were exposed to $100 \mathrm{nM}$ of hemi-MPO or $100 \mathrm{nM}$ of dimeric MPO or $1 \mu \mathrm{M}$ of ionomycin (as a positive control) and the aliquots were sampled every minute to detect changes in Fluor-3 fluorescence $(525 \mathrm{~nm})$ excited at $488 \mathrm{~nm}$.

Both flow cytometric assays were performed on a Navios (Beckman Coulter, USA) system.

\section{Statistical analysis}

Data are expressed as mean \pm SD or mean \pm SEM, as indicated in the captions to the figures and tables. To analyze differences between mean values of the two groups, the Student $t$ test was used. Differences between mean values of more than two groups were analyzed by ANOVA followed by Student-Newman-Keuls test. Statistical analysis was performed using Origin 7.0 (Northampton, USA) or Statistica software. A $p$ value $<0.05$ was considered to be significant.

\section{Results}

Interaction of RBCG proteins with hemi-MPO

Recently, it was shown that binding of dimeric MPO to RBC surface is based mostly on electrostatic interactions with the participation of sialic acids and its main targets are band 3 protein (B3) and glycophorin A and B [13,31]. To check if hemi-MPO binds to the same targets on RBC surface, RBCG proteins were separated by SDS-PAGE (Fig. 1, panel 1) and transferred to a nitrocellulose membrane. Their interaction with hemi-MPO and dimeric MPO were analyzed using ligand Western blotting, using rabbit anti-MPO antibodies labeled with horseradish peroxidase. Rabbit antibodies against MPO did not react with RBCG proteins without
306

0

1

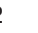

4




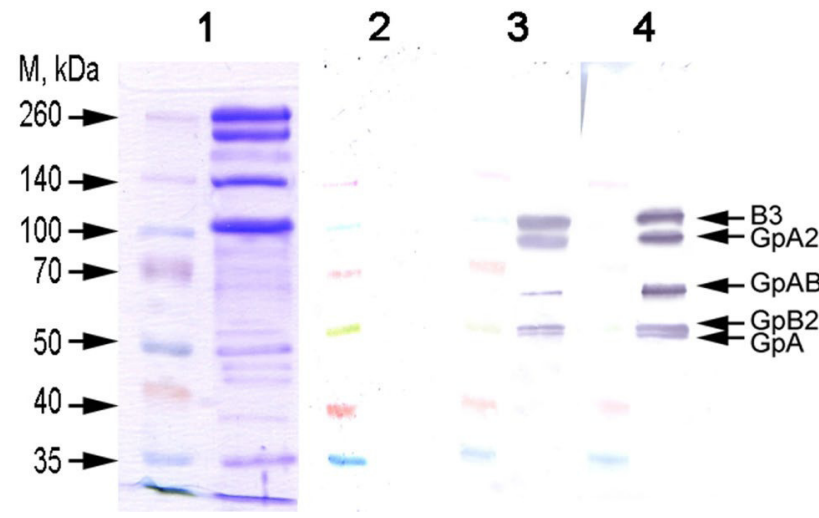

Fig. 1 Binding of human MPO to RBCG proteins. Prestained protein marker (the left lanes in each panel) and RBCG proteins (100 $\mu \mathrm{g}$ per line) separated by SDS-PAGE and transferred on nitrocellulose membranes: panel 1-Coomassie brilliant blue R-250 staining; panel 2, 3 and 4-ligand Western blot staining using: no MPO (panel 2), $200 \mathrm{nM}$ dimeric MPO (panel 3) and $200 \mathrm{nM}$ hemi-MPO (panel 4) and horseradish peroxidase (HRP)-labeled rabbit anti-human MPO antibody $(10 \mu \mathrm{g} / \mathrm{ml})$ of membranes. Arrows represent protein standards (on the left) or positions of specific RBCG proteins and their dimers (on the right)

preliminary addition of MPO (Fig. 1, panel 2). The membrane showed that five dimeric MPO-binding regions were revealed using ligand Western blot assay (Fig. 1, panel 3) corresponding to the band 3 protein (B3) and glycophorin A and B (GpA2, GpAB, GpB2, GpA). These glycoproteins were identified earlier with help of periodic acid-Schiff reagent and by mass-spectrometry [13]. Similar patterns of hemi-MPO binding to the five protein areas were detected (Fig. 1, panel 4). These results indicate that hemi-MPO as well as the dimeric MPO binds to the band 3 protein and glycophorin A and B of the RBC plasma membrane.

To be sure that hemi- and dimeric MPO stably bind to $\mathrm{RBC}$ surface proteins in their native environment, we incubated washed RBCs with MPO isoforms for $15 \mathrm{~min}$ and then measured MPO concentration in cell supernatants as described earlier [32]. The decrease of dimeric MPO as well as hemi-MPO content in cell supernatant (Supplementary Materials, Fig.S1) indicates that both isoforms stably bind with RBCs.

\section{Effect of hemi-MPO on the RBC elastic properties and their resistance to hemolysis}

Hemolysis was initiated by reducing the ionic strength of the medium (osmotic hemolysis) or $\mathrm{pH}$ (acidic hemolysis). As shown in Fig. 2a, b hemi-MPO as well as dimeric MPO augmented acidic and osmotic hemolysis in a dosedependent manner. Thus, the degree of osmotic hemolysis (Fig. 2c) increased, and the half-time of acidic hemolysis decreased (Fig. 2d) for RBCs treated with both MPO forms in comparison to control, indicating a decrease in cell resistance to hemolysis. However, the effect of hemi-MPO was lower in comparison with native dimeric MPO (Fig. 2c, d). It should be noted, that unrelated to MPO positively charged protein human lactoferrin (hLF) with molecular mass $76 \mathrm{kDa}$ similar to that of hemi-MPO did not affect acidic and osmotic hemolysis (data not shown) indicating the specificity of MPO isoforms' effect on RBC resistant to hemolysis.

As MPO can induce the production of hypohalous acids, which are known to initiate RBC hemolysis [33, 34], we next examined the observed effects in the presence of MPO enzymatic activity inhibitor - 4-ABH. As shown in Fig. 2e 4-ABH $(50 \mu \mathrm{M})$ failed to abrogate hemi-MPO-mediated increase in hemolysis. Furthermore, under hypotonic and acidic conditions (used in present study) MPO peroxidase activity decreased by at least $97 \%$. ABH $(50 \mu \mathrm{M})$ almost completely suppressed the rest of MPO enzymatic activity (data not shown).

Differences in the hemi-MPO and dimeric MPO effects on RBC mechanical properties were also shown by AFM. To assess the RBC surface elastic properties and cell stiffness, we determined the local Young's modulus for intact RBCs and RBCs treated with both MPO isoforms (Fig. 2f). Hemi-MPO and dimeric MPO caused increase of Young's modulus values by approximately $10 \%$ and $30 \%$, respectively (Fig. 2f). These data indicate that both MPO isoforms lead to RBC membrane stabilization and increase in their mechanical stiffness but to a various stage.

Thus, it can be concluded, that binding of hemi-MPO, as well as native MPO with RBC plasma membrane, initiates similar changes in cell structural and functional properties. These hemi-MPO effects do not depend on the catalytic activity of the enzyme and are rather weaker than in the case of dimeric MPO.

\section{Effect of hemi-MPO on size and morphology of RBCs}

We have recently shown that $\mathrm{RBC}$ treatment with native dimeric MPO led to their volume increase, as evidenced by a marked increase in the number of stomatocytes and microspherocytes [13]. Moreover, the maximum change in cell morphology occurred within the first two min and then the cells reverted back to the morphology of normocytes. In this work, we examined the effect of hemi-MPO on cell morphology and compared it with the effect of dimeric MPO.

During the period of observation $(15 \mathrm{~min})$ the morphology of control (untreated) RBCs did not change over time. As expected dimeric MPO addition to RBCs suspension induced cell swelling during the first $15 \mathrm{~s}$ as was evidenced by appearance of significant amounts of stomatocytes (Fig. 3e), reduction in echinocyte number (Fig. 3b) and afterAQ2 5 15 min of observation led to significant rise in the number

\begin{tabular}{|l|l|l|l|l|}
\hline Journal : Large 11010 & Article No : 3654 & Pages : 12 & MS Code : 3654 & Dispatch : 15-11-2019 \\
\hline
\end{tabular}



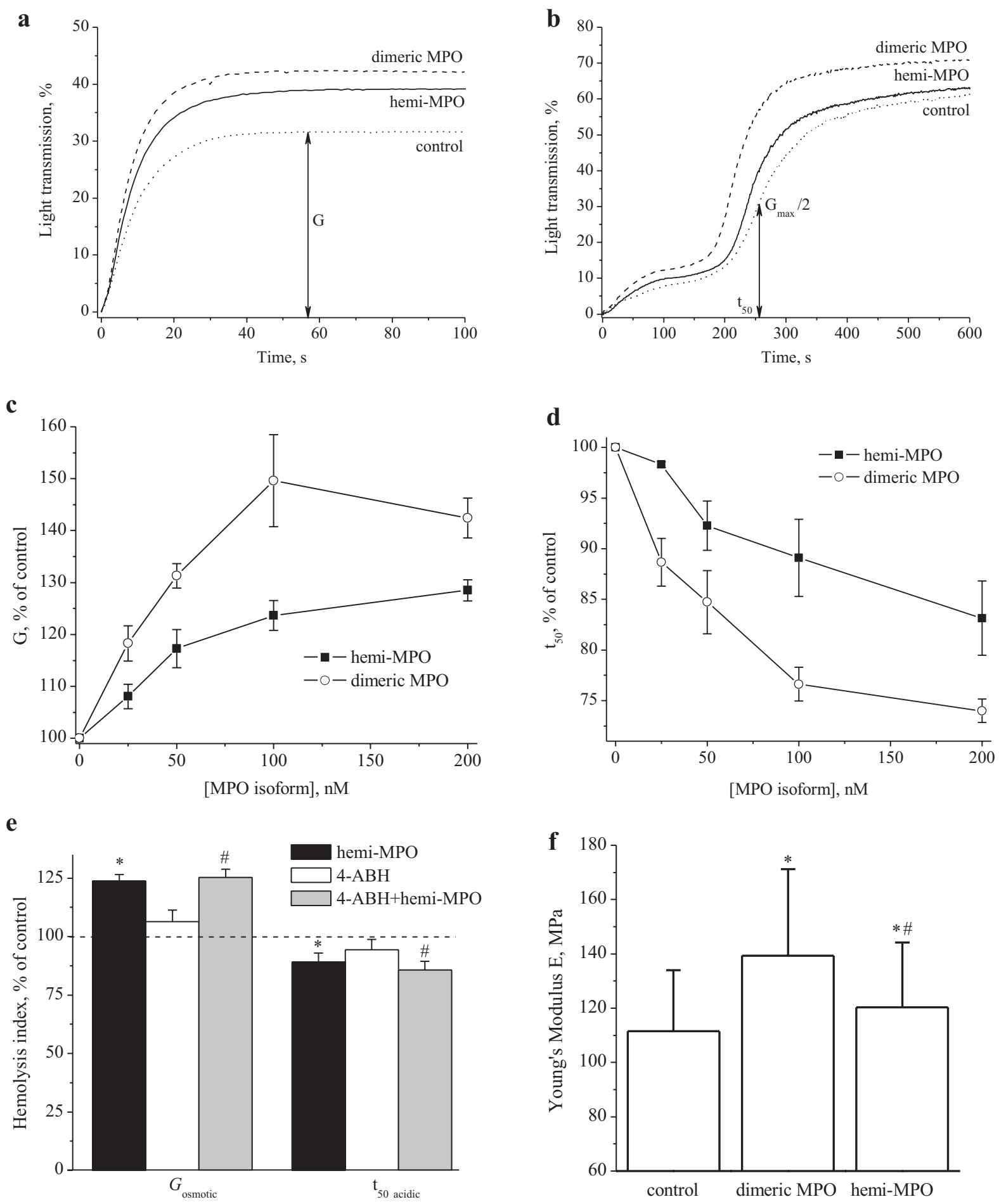

Fig. 2 Effects of MPO isoforms on hemolysis and RBC membrane elasticity. a, b Typical kinetics of osmotic $(60 \mathrm{mM} \mathrm{NaCl})$ (a) and acidic (4.1 mM Na $2 \mathrm{HPO}_{4} / 7.9 \mathrm{mM}$ citric acid, $155 \mathrm{mM} \mathrm{NaCl}$; $\mathrm{pH} 2.9$ ) (b) RBC hemolysis in the absence (control) and presence of dimeric and hemi-MPO $(100 \mathrm{nM})$. c, d The degree $(G)$ and the half-time $\left(t_{50}\right)$ of osmotic (c) and acidic (d) hemolysis in the presence of different concentration dimeric and hemi-MPO. e The effect of specific inhibitor of MPO enzymatic activity 4-ABH $(50 \mu \mathrm{M})$ on the degree of

osmotic $\left(G_{\text {osmotic }}\right)$ and the half-time of acidic $\left(t_{50 \text { acidic }}\right)$ RBC hemolysis in the presence of hemi-MPO $(100 \mathrm{nM})$. The hemolysis index of control MPO untreated RBCs was $100 \%$. f The influence of MPO isoforms $(25 \mathrm{nM})$ on the Young's modulus of RBCs. The data are presented as mean $\pm \mathrm{SD}[n=3-5(\mathbf{a}-\mathbf{e})$ or $n=23-26(\mathbf{f})] * p<0.05$ compared to control, $\# p<0.05$ compared to the effect of $4-\mathrm{ABH}(\mathbf{e})$ or dimeric MPO (f)

\begin{tabular}{|l|l|l|l|l|}
\hline Journal : Large 11010 & Article No : 3654 & Pages : 12 & MS Code : 3654 & Dispatch : 15-11-2019 \\
\hline
\end{tabular}


Fig. 3 Changes in RBC morphology after incubating the cells with dimeric MPO $(100 \mathrm{nM})$ or hemi-MPO $(100 \mathrm{nM})$. The number (in \%) of normocytes (a), echinocytes (b), cup-shaped cells (c), microspherocytes (d) and stomatocytes (e) was calculated for $15 \mathrm{~s}$, $2 \mathrm{~min}$, and $15 \mathrm{~min}$ after MPO addition. The data are presented as mean \pm SEM $(n=500-550) . * p<0.05$ comparing means to untreated control

of microspherocytes (Fig. 3d). Although hemi-MPO did not induce significant changes in the number of stomatocytes and echinocytes (Fig. 3e, b), the final increase in the number of microspherocytes was significant (Fig. 3d), however, this effect was less pronounced than in the case of dimeric MPO.

It should be noted that the observed appearance of microspherocytes in cell suspension indicates about the MPOinduced increase in cell volume. Indeed, changes in RBC volume, induced by both MPO isoforms, were observed by AFM (Fig. 4, Table 1). It was shown that RBCs treatment with dimeric MPO led to a decrease in concave depth, as evidenced by a significant change in the parameters $h$ and $k$, while other linear cell sizes (height, $H$ and diameter, $d$ ) were unaffected (Table 1, Fig. 4c). In the presence of hemiMPO, a decrease of the relative concave depth $(k)$ was also observed, however, this change was lower, compared to native dimeric MPO (Fig. 4).

Thus, the obtained results indicate that hemi-MPO, similarly to the dimeric isoform of the enzyme, induces changes in RBC morphology and increase in their volume, but to a much lesser extent than dimeric MPO.

\section{Hemi-MPO effect on RBC membrane potential}

Changes in morphology and RBC volume are closely linked to ionic conductivity of plasma membrane. Thus, recently, we have shown that MPO-induced increase in RBC volume is associated with depolarization of plasma membrane, while the subsequent restoration of cell morphology and volume-with plasma membrane hyperpolarization [13]. In the present work, we also examined whether hemi-MPO had an influence on RBC membrane potential. Using a "cellattach" patch clamp technique, it was shown, that like in the case with dimeric MPO, the addition of hemi-MPO to RBC suspension induced a two-stage change in membrane potential: fast membrane depolarization, followed by a prolonged hyperpolarization (more than $10 \mathrm{~min}$ ) (Fig. 5a). As expected, the effect of hemi-MPO at both stages: depolarization and hyperpolarization were lower compared to dimeric isoform of MPO (Fig. 5a, b).

It should be noted, that all described changes in structural and functional properties of RBCs, induced by both MPO isoforms, were observed only in the medium containing $\mathrm{Ca}^{2+}$ ions. No apparent changes in morphology, cell sizes or ion permeability occurred in calcium-free medium (data not shown). Actually, we have shown previously [13], that
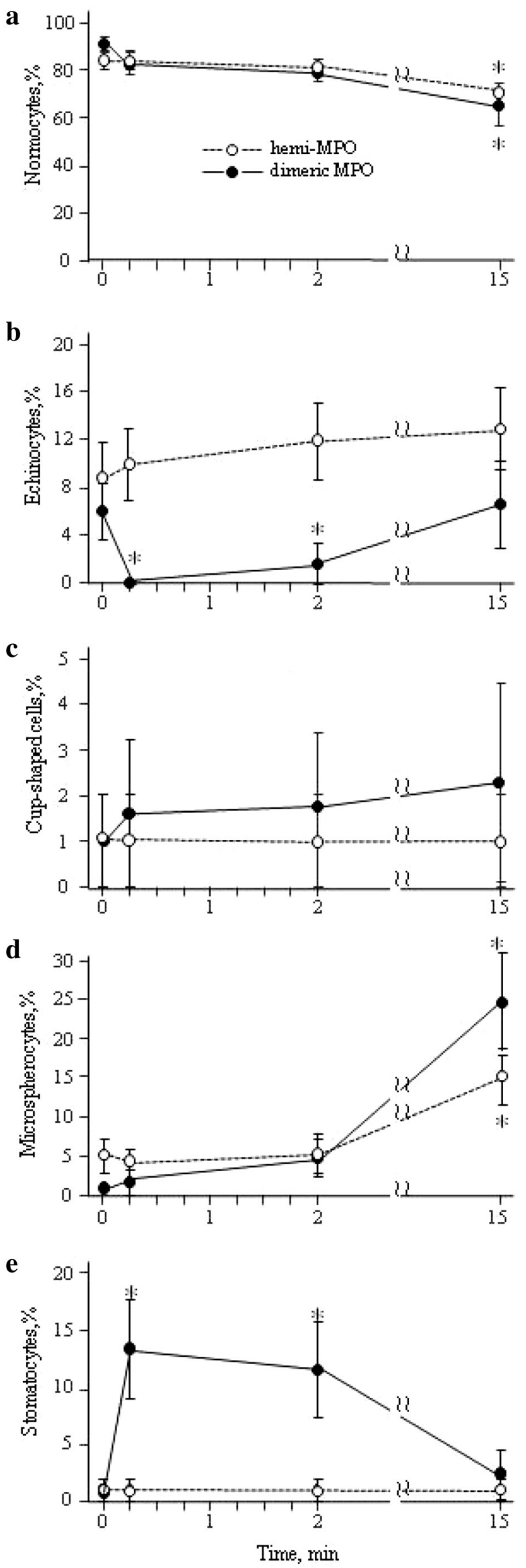
a

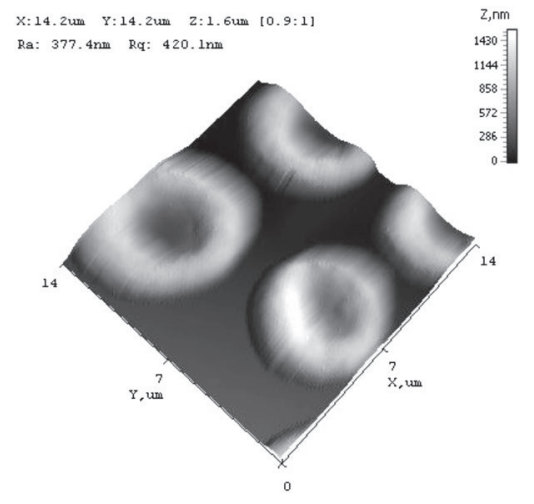

b

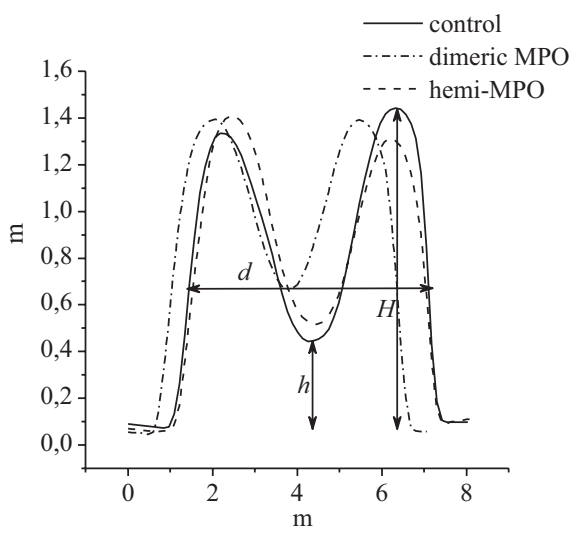

c

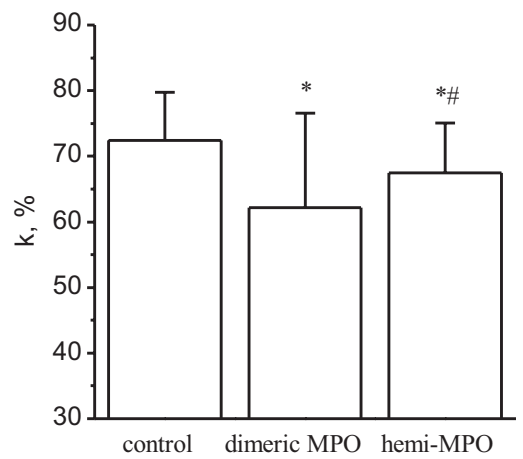

Fig. 4 AFM-images and surface topography of RBCs. a AFM 3D-image of RBCs fixed with $1.5 \%$ glutaraldehyde for $30 \mathrm{~min}$. b The profiles of the RBC treated with dimeric MPO (100 nM), hemi-MPO $(100 \mathrm{nM})$, or the vehicle (control), used to calculate cell diameter $d$ maximal cell height $(H)$, concave height $(h)$, and relative concave

Table 1 Changes in RBC size in the presence of dimeric and hemiMPO (100 nM)

\begin{tabular}{llll}
\hline & $H, \mu \mathrm{m}$ & $h, \mu \mathrm{m}$ & $d, \mu \mathrm{m}$ \\
\hline Control & $1.36 \pm 0.15$ & $0.40 \pm 0.15$ & $5.64 \pm 0.29$ \\
Dimeric MPO & $1.36 \pm 0.14$ & $0.51 \pm 0.43^{*}$ & $5.45 \pm 0.36$ \\
Hemi-MPO & $1.35 \pm 0.15$ & $0.42 \pm 0.08 \#$ & $5.46 \pm 0.46$ \\
\hline
\end{tabular}

$H$ RBC height (maximum height of the cell), $h$ RBC concave height (minimum height of the cell), $d \mathrm{RBC}$ diameter. The data are presented as mean \pm SD $(n=52-58) * p<0.05$ compared with control, $\# p<0.05$ compared with the effect of dimeric MPO

a

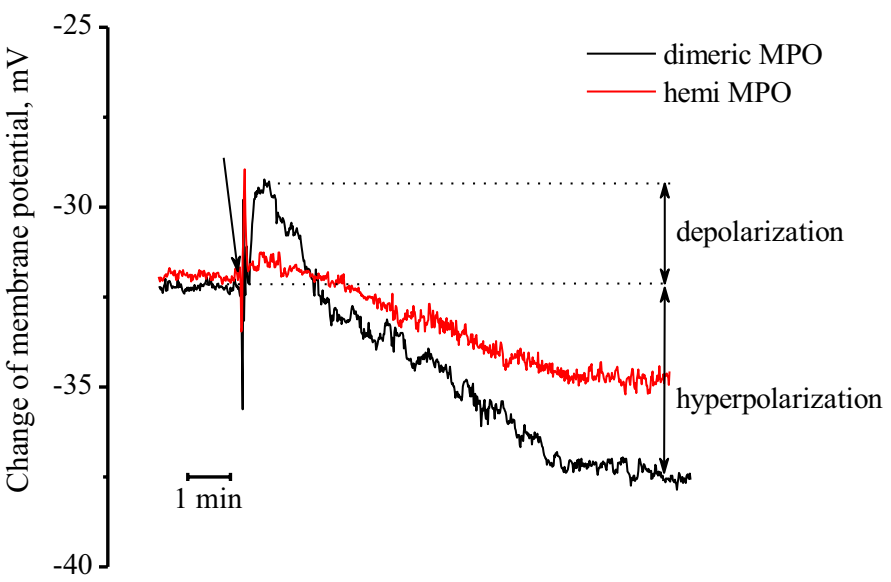

depth, calculated as: $k=(H-h) / h \cdot 100 \%$. c Changes in the relative concave depth of the RBC $(k)$ after 2 min incubation with dimeric or hemi-MPO $(100 \mathrm{nM})$. The data are presented as mean \pm SD $(n=52-58) . * p<0.05$ comparing means to untreated control, $\# p<0.05$ comparing means to the effect of dimeric MPO

binding of native MPO to RBC plasma membrane induces $\mathrm{Ca}^{2+}$ entry into the cytosol of cells. In present work, hemiMPO was also capable to induce rise in cytosolic $\mathrm{Ca}^{2+}$ concentration as measured by flow cytometry in Fluor-3 loaded RBCs (Fig. 6) but this effect was lower compared to the $\mathrm{Ca}^{2+}$-response induced by dimeric MPO and $\mathrm{Ca}^{2+}$-ionophore ionomycine.

Since intracellular $\mathrm{Ca}^{2+}$-rise can activate phospholipid scramblase, that bidirectionally and nonspecifically transports phospholipids, leading to PS exposure on cell external
Fig. 5 Effect of MPO isoforms on RBC membrane potential. a The kinetics of membrane potential induced by dimeric or hemi-MPO $(100 \mathrm{nM})$, which show depolarization and hyperpolarization phases. b Values of depolarization and hyperpolarization effects of MPO b

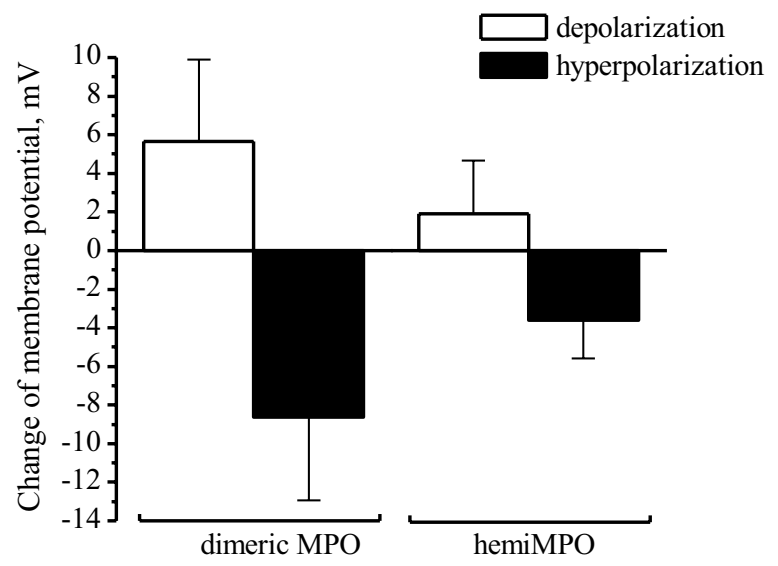

isoforms on RBC membrane potential. Arrow indicates the moment of MPO isoform addition. The data are presented as mean \pm SD $(n=7-8)$

\begin{tabular}{|l|l|l|l|l|}
\hline Journal : Large 11010 & Article No : 3654 & Pages : 12 & MS Code : 3654 & Dispatch : 15-11-2019 \\
\hline
\end{tabular}




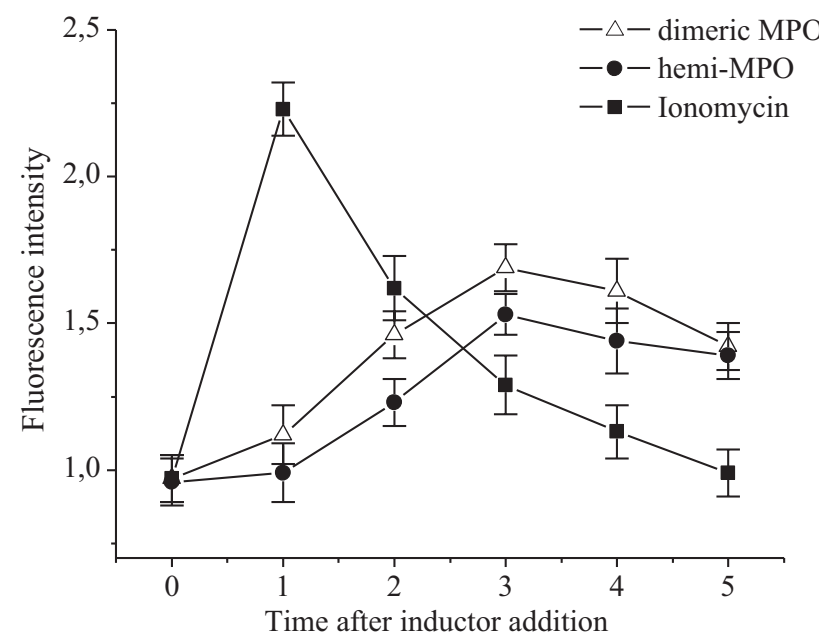

Fig. 6 Effect of MPO isoforms on cytosolic $\mathrm{Ca}^{2+}$ concentration. Changes in mean fluorescence intensity of Fluor-3 loaded RBCs, treated with dimeric MPO $(100 \mathrm{nM})$, hemi-MPO $(100 \mathrm{nM})$ or ionomycin $(1 \mu \mathrm{M})$, detected by flow cytometry assay. The data are presented as mean $\pm \mathrm{SD}(n=3-5)$

leaflet [35] and considering recent data, that PS exposure is controlled by membrane hyperpolarization due to $\mathrm{Ca}^{2+}$-dependent Gardos channel opening [36], it was intriguing to investigate if native dimeric and hemi-MPO lead to PS exposure on the RBC's membrane.

\section{PS exposure in RBCs, treated with dimeric and hemi-MPO}

To determine if MPO isoforms are able to induce PS exposure on the outer RBC's leaflet, cells were preincubated with native dimeric or hemi-MPO for $15 \mathrm{~min}$ and stained with annexin $\mathrm{V}$ for PS detection by flow cytometry. As a positive control, we used calcium ionophore ionomycin $(1 \mu \mathrm{M})$ and PKC activator PMA $(5 \mu \mathrm{M})$, which were shown to induce PS exposure in RBCs [36-38]. As shown on Fig. 7 RBC treatment with both dimeric MPO and hemi-MPO led to a significant increase in PS exposure by $34 \%$ and $22 \%$, respectively. The effect of dimeric MPO was comparable to that of ionomycin and PMA. However, according to the previous results, the effect of hemi-MPO was less pronounced.

\section{Discussion}

Today, along with wide investigation of MPO enzymatic activity, great attention is paid to its ability to bind to plasma membrane of blood cells and regulate their structural and functional properties. This ability doesn't depend on the catalytic activity of the enzyme, but is largely due to the peculiarities of the structure of the MPO molecule. In this

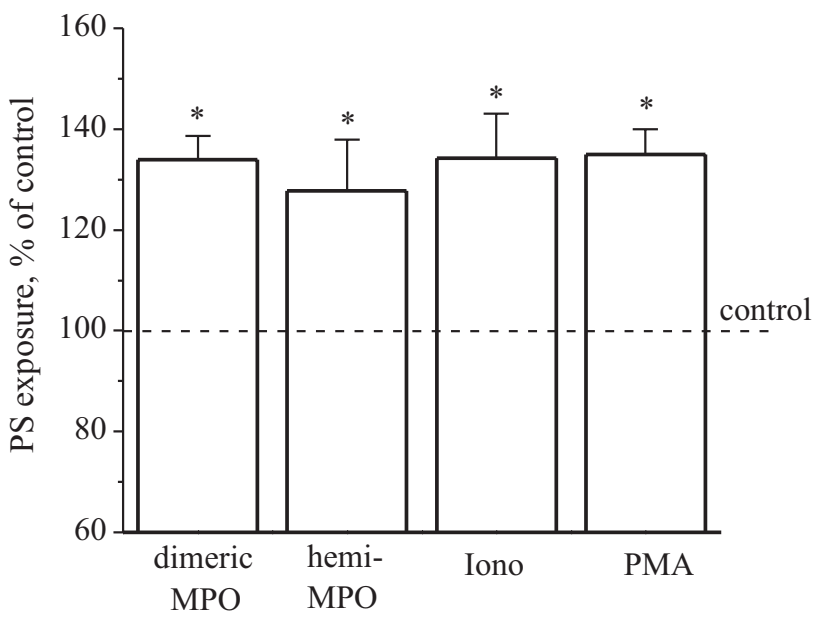

Fig. 7 Effect of MPO isoforms on PS exposure on the outer leaflet of RBCs. Prior annexin V-Alexa Fluor 647 staining RBCs were pretreated with dimeric MPO $(100 \mathrm{nM})$, hemi-MPO (100 nM), PMA $(5 \mu \mathrm{M})$, ionomycin $(1 \mu \mathrm{M})$ or the vehicle (control) for $15 \mathrm{~min}$ at room temperature in $\mathrm{PBS}$, containing $2 \mathrm{mM} \mathrm{CaCl}_{2}$. PS exposure (Annexin $\mathrm{V}$ binding) was determined by change in mean fluorescence intensity, $\%$ of control. The data are presented as mean \pm SD $(n=3-4)$. $* p<0.05$ comparing means to untreated control

work, we have shown, that the decomposition of dimeric MPO into monomers is accompanied by a decrease in its ability to regulate the structural and functional properties of red blood cells.

The peculiarity of MPO structure is that mature MPO, which is stored in azurophilic granules of fully differentiated neutrophils, is a dimer $(\sim 145 \mathrm{kDa})$, consisting of identical heme-containing protomers connected by a disulfide bond. Native dimeric MPO is able to bind to the plasma membrane and regulate the functional responses of various cells.

Thus, binding of native MPO to CD11b/CD18, a major neutrophil adhesion receptor, leads to tyrosine phosphorylation of a number of proteins and as a result stimulates degranulation [12], adhesion, and also increases the survival of these cells [39]. However, as has been shown previously [20], abnormal MPO conformation is accompanied by a decrease in its ability to regulate the functional activity of neutrophils. The reductive alkylation of MPO leads to its inability to enhance neutrophil adhesion [40]. Recently, we have shown that hemi-MPO, as well as MPO modified by hypochlorous acid (MPO-HOCl), lost its ability to prime NADPH-oxidase of neutrophils [20]. In addition, it was found that hemi-MPO to a much lesser extent than dimeric MPO-stimulated rise in cytosolic calcium and lysozyme exocytosis in neutrophils, and the capacity of monomeric MPO to delay apoptosis of neutrophils and increase their lifespan was weaker than that of dimeric MPO [20].

Previous studies with RBCs demonstrated that MPO$\mathrm{HOCl}$, in contrast to native dimeric MPO, lost its ability

\begin{tabular}{|l|l|l|l|l|}
\hline Journal : Large 11010 & Article No : 3654 & Pages : 12 & MS Code : 3654 & Dispatch : 15-11-2019 \\
\hline
\end{tabular}


to bind to plasma membrane of $\mathrm{RBC}$ and regulate their structural and functional properties [13]. Apparently, this effect was due to a decrease in the net positive charge of the MPO molecule, resulted from halogenation of its amino groups by $\mathrm{HOCl}$, that led to a decrease in the electrostatic interaction with negatively charged RBC plasma membrane proteins. In present study, we have shown for the first time that in contrast to MPO-HOCl [13], hemiMPO, obtained from native MPO by disulfide cleavage, retained the ability of the enzyme to bind to RBC surface (Fig. 1). Since dimeric MPO dissociation into two hemiMPO molecules due to disulfide bond reduction preserves the charge of the hemi-MPO molecules, then, apparently, the electrostatic interaction of hemi-MPO with RBC proteins is conserved.

Binding of hemi-MPO, as well as binding of dimeric MPO with RBC's membrane proteins, reduced cell resistance to osmotic and acidic hemolysis as well as cell elasticity (Fig. 2), led to significant changes in cell volume, morphology (Table 1, Figs. 3, 4), the conductance of plasma membrane ion channels (Fig. 5) and cytosolic $\mathrm{Ca}^{2+}$ concentration of RBCs (Fig. 6). It has been shown for the first time that both dimeric and hemi-MPO contribute to the formation of PS-positive RBCs (Fig. 7). These results are of great importance, as the exposure of PS on the outer membrane leaflet of RBCs serves as a signal for eryptosis, a mechanism for the RBC clearance from blood circulation and also lead to adhesion of RBCs to endothelium in some diseases such as sickle cell anemia, malaria, and diabetes [41].

However, the effects of hemi-MPO on the structural and functional properties of RBCs were lower compared with those of dimeric MPO. The possible reason is the presence of two receptor-binding sites on native dimeric MPO molecule in contrast to one binding site for hemi-MPO. Dimeric MPO, being a bivalent ligand, when binds to its corresponding receptors, can lead to their clustering that may have a significant effect on intracellular signaling [42, 43]. On the other hand, it was shown that MPO-binding proteins on RBC membrane: band 3 protein and glycophorin A, form a complex $[44,45]$. Furthermore, as bivalent ligands may possess higher binding affinity to clustered receptors compared to monovalent ligands [42, 43], dimeric MPO effect on the structural and functional RBC properties may be more pronounced compared to hemi-MPO.

Thus, the ability of MPO protein to influence RBC's biophysical properties depends on its conformation (dimeric or monomeric isoform). It is intriguing to speculate that hemiMPO appearance in blood during inflammation, as it was shown earlier [20], can serve as a regulatory mechanism addressed to reduce abnormalities on RBC response.

Acknowledgements This work was partly supported by Russian Foundation for Basic Research (Grant 18-515-00004, Grant 17-54-04009) and Belarusian Republican Foundation for Fundamental Research (Grant B18R-058).

\section{Compliance with ethical standards}

Conflict of interest The authors declare no competing financial and nonfinancial interests.

Ethical approval This work was approved by the protocol of the Local Ethics Committee at Federal State Budgetary Scientific Institution "Institute of Experimental Medicine".

\section{References}

1. Furtmüller PG, Burner U, Obinger C (1998) Reaction of myeloperoxidase compound I with chloride, bromide, iodide, and thiocyanate. Biochemistry 37(51):17923-17930. https://doi. org/10.1021/bi9818772

2. Davies MJ, Hawkins CL, Pattison DI, Rees MD (2008) Mammalian heme peroxidases: from molecular mechanisms to health implications. Antioxid Redox Signal 10(7):1199-1234. https:// doi.org/10.1089/ars.2007.1927

3. Morgan PE, Pattison DI, Talib J, Summers FA, Harmer JA, Celermajer DS, Hawkins CL, Davies MJ (2011) High plasma thiocyanate levels in smokers are a key determinant of thiol oxidation induced by myeloperoxidase. Free Radic Biol Med 51(9):18151822. https://doi.org/10.1016/j.freeradbiomed.2011.08.008

4. Chandler JD, Day BJ (2015) Biochemical mechanisms and therapeutic potential of pseudohalide thiocyanate in human health. Free Radic Res 49(6):695-710. https://doi.org/10.3109/10715 762.2014.1003372

5. Pattison DI, Davies MJ (2006) Reactions of myeloperoxidasederived oxidants with biological substrates: gaining chemical insight into human inflammatory diseases. Curr Med Chem 13(27):3271-3290. https://doi.org/10.2174/092986706778773095

6. Panasenko OM, Gorudko IV, Sokolov AV (2013) Hypochlorous acid as a precursor of free radicals in living systems. Biochemistry (Moscow) 78(13):1466-1489. https://doi.org/10.1134/S0006 297913130075

7. Panasenko OM, Sergienko VI (2010) Halogenizing stress and its biomarkers [Article in Russian]. Vestn Ross Akad Med Nauk 1:27-39

8. Yap YW, Whiteman M, Cheung NS (2007) Chlorinative stress: an under appreciated mediator of neurodegeneration? Cell Signal 19(2):219-228. https://doi.org/10.1016/j.cellsig.2006.06.013

9. Gorudko IV, Sokolov AV, Shamova EV, Grudinina NA, Drozd ES, Shishlo LM, Grigorieva DV, Bushuk SB, Bushuk BA, Chizhik SA, Cherenkevich SN, Vasilyev VB, Panasenko OM (2013) Myeloperoxidase modulates human platelet aggregation via actin cytoskeleton reorganization and store-operated calcium entry. Biol Open 2(9):916-923. https://doi.org/10.1242/bio.20135314

10. Kolarova H, Klinke A, Kremserova S, Adam M, Pekarova M, Baldus S, Eiserich JP, Kubala L (2013) Myeloperoxidase induces the priming of platelets. Free Radic Biol Med 61:357-369. https ://doi.org/10.1016/j.freeradbiomed.2013.04.014

11. Klinke A, Nussbaum C, Kubala L, Friedrichs K, Rudolph TK, Rudolph V, Paust HJ, Schröder C, Benten D, Lau D, Szocs K, Furtmüller PG, Heeringa P, Sydow K, Duchstein HJ, Ehmke H, Schumacher U, Meinertz T, Sperandio M, Baldus S (2011) Myeloperoxidase attracts neutrophils by physical forces. Blood 117(4):1350-1358. https://doi.org/10.1182/blood-2010-05-28451 3 
12. Lau D, Mollnau H, Eiserich JP, Freeman BA, Daiber A, Gehling UM, Brümmer J, Rudolph V, Münzel T, Heitzer T, Meinertz T, Baldus S (2005) Myeloperoxidase mediates neutrophil activation by association with CD11b/CD18 integrins. Proc Natl Acad Sci USA 102(2):431-436. https://doi.org/10.1073/pnas.04051 93102

13. Gorudko IV, Sokolov AV, Shamova EV, Grigorieva DV, Mironova EV, Kudryavtsev IV, Gusev SA, Gusev AA, Chekanov AV, Vasilyev VB, Cherenkevich SN, Panasenko OM, Timoshenko AV (2016) Binding of human myeloperoxidase to red blood cells: molecular targets and biophysical consequences at the plasma membrane level. Arch Biochem Biophys 591:87-97. https://doi. org/10.1016/j.abb.2015.12.007

14. Benson TW, Weintraub NL, Kim HW, Seigler N, Kumar S, Pye J, Horimatsu T, Pellenberg R, Stepp DW, Lucas R, Bogdanov VY, Litwin SE, Brittain JE, Harris RA (2018) A single high-fat meal provokes pathological erythrocyte remodeling and increases myeloperoxidase levels: implications for acute coronary syndrome. Lab Invest 98(10):1300-1310. https://doi.org/10.1038/s4137 4-018-0038-3

15. Blair-Johnson M, Fiedler T, Fenna R (2001) Human myeloperoxidase: structure of a cyanide complex and its interaction with bromide and thiocyanate substrates at $1.9 \AA$ resolution. Biochemistry 40(46):13990-13997. https://doi.org/10.1021/bi0111808

16. Yamada M, Mori M, Sugimura T (1981) Myeloperoxidase in cultured human promyelocytic leukemia cell line HL-60. Biochem Biophys Res Commun 98(1):219-226. https://doi. org/10.1016/0006-291X(81)91891-X

17. Yamada M, Mori M, Sugimura T (1983) Myeloperoxidase of human myeloid leukemia cells HL-60 drown in culture and in nude mice. J Biochem 93(6):1661-1668

18. Andrews PC, Krinsky NI (1981) The reductive cleavage of myeloperoxidase in half, producing enzymically active hemi-myeloperoxidase. J Biol Chem 256(9):4211-4218

19. Gorudko IV, Mikhalchik EV, Sokolov AV, Grigorieva DV, Kostevich VA, Vasilyev VB, Cherenkevich SN, Panasenko OM (2017) The production of reactive oxygen and halogen species by neutrophils in response to monomeric forms of myeloperoxidase. Biophysics 62(6):919-925. https://doi.org/10.1134/S000635091 7060069

20. Gorudko IV, Grigorieva DV, Sokolov AV, Shamova EV, Kostevich VA, Kudryavtsev IV, Syromiatnikova ED, Vasilyev VB, Cherenkevich SN, Panasenko OM (2018) Neutrophil activation in response to monomeric myeloperoxidase. Biochem Cell Biol 96(5):592-601. https://doi.org/10.1139/bcb-2017-0290

21. Zuurbier KW, van den Berg JD, Van Gelder BF, Muijsers AO (1992) Human hemi-myeloperoxidase. Initial chlorinating activity at neutral $\mathrm{pH}$, compound II and III formation, and stability towards hypochlorous acid and high temperature. Eur J Biochem 205(2):737-742. https://doi.org/10.1111/j.1432-1033.1992.tb168 37.x

22. Gorudko IV, Cherkalina OS, Sokolov AV, Pulina MO, Zakharova ET, Vasil'ev VB, Cherenkevich SN, Panasenko OM (2009) New approaches to the measurement of the concentration and peroxidase activity of myeloperoxidase in human blood plasma. Bioorg Khim 35(5):629-639. https://doi.org/10.1134/S10681620090500 57 (Russian)

23. Hope HR, Remsen EE, Lewis C Jr, Heuvelman DM, Walker MC, Jennings M, Connolly DT (2000) Large-scale purification of myeloperoxidase from HL60 promyelocytic cells: characterization and comparison to human neutrophil myeloperoxidase. Protein Expr Purif 18(3):269-276. https://doi.org/10.1006/prep.1999.1197

24. Sokolov AV, Kostevich VA, Zakharova ET, Samygina VR, Panasenko OM, Vasilyev VB (2015) Interaction of ceruloplasmin with eosinophil peroxidase as compared to its interplay with myeloperoxidase: reciprocal effect on enzymatic properties.
Free Radic Re 49(6):800-811. https://doi.org/10.3109/10715 762.2015.1005615

25. Vakhrusheva TV, Sokolov AV, Kostevich VA, Vasilyev VB, Panasenko OM (2018) Enzymatic and bactericidal activity of monomeric and dimeric forms of myeloperoxidase. Biochem Moscow Suppl Ser B 12(3):258-265. https://doi.org/10.1134/ S1990750818030083

26. Fling SP, Gregerson DS (1986) Peptide and protein molecular weight determination by electrophoresis using a high-molarity tris buffer system without urea. Anal Biochem 155(1):83-88. https:// doi.org/10.1016/0003-2697(86)90228-9

27. Anderson NL, Nance SL, Pearson TW, Anderson NG (1982) Two-dimensional electrophoretic patterns of human plasma membrane proteins immobilized on nitrocellulose. Electrophoresis 3:135-142

28. Sokolov AV, Pulina MO, Ageeva KV, Tcherkalina OS, Zakharova ET, Vasilyev VB (2009) Identification of complexes formed by ceruloplasmin with matrix metalloproteinases 2 and 12. Biochemistry (Mosc) 74(12):1388-1392. https://doi.org/10.1134/S0006 297909120141

29. Drozd ES, Chizhik SA (2008) Combined atomic force microscopy and optical microscopy measurements as a method of erythrocyte investigation. Proc SPIE. https://doi.org/10.1117/12.836481

30. Mathur AB, Collinsworth AM, Reichert WM, Kraus WE, Truskey GA (2001) Endothelial, cardiac muscle and skeletal muscle exhibit different viscous and elastic properties as determined by atomic force microscopy. J Biomech 34(12):1545-1553. https:// doi.org/10.1016/S0021-9290(01)00149-X

31. Adam M, Gajdova S, Kolarova H, Kubala L, Lau D, Geisler A, Ravekes T, Rudolph V, Tsao PS, Blankenberg S, Baldus S, Klinke A (2014) Red blood cells serve as intravascular carriers of myeloperoxidase. J Mol Cell Cardiol 74:353-363. https://doi. org/10.1016/j.yjmcc.2014.06.009

32. Gorudko IV, Cherkalina OS, Sokolov AV, Pulina MO, Zakharova ET, Vasilyev VB, Cherenkevich SN, Panasenko OM (2009) New approaches to the measurement of the concentration and peroxidase activity of myeloperoxidase in human blood plasma. Bioorgan Khim 35:629-639

33. Zavodnik LB, Zavodnik IB, Lapshyna EA, Buko VU, Bryszewska MJ (2002) Hypochlorous acid-induced membrane pore formation in red blood cells. Bioelectrochemistry 58(2):157-161. https://doi. org/10.1016/S1567-5394(02)00151-2

34. Zavodnik LB, Zavodnik IB, Lapshina EA, Shkodich AP, Bryszewska M, Buko VU (2000) Hypochlorous acid-induced lysis of human erythrocytes. Inhibition of cellular damage by the isoflavonoid genistein-8-C-glucoside. Biochemistry (Mosc) 65(8):946-951

35. Bevers EM, Williamson PL (2010) Phospholipid scramblase: an update. FEBS Lett 584(13):2724-2730. https://doi.org/10.1016/j. febslet.2010.03.020

36. Wesseling MC, Wagner-Britz L, Huppert H, Hanf B, Hertz L, Nguyen DB, Bernhardt I (2016) Phosphatidylserine exposure in human red blood cells depending on cell age. Cell Physiol Biochem 38(4):1376-1390. https://doi.org/10.1159/000443081

37. Jacobi J, Lang E, Bissinger R, Frauenfeld L, Modicano P, Faggio C, Abed M, Lang F (2014) Stimulation of erythrocyte cell membrane scrambling by mitotane. Cell Physiol Biochem 33(5):15161526. https://doi.org/10.1159/000358715

38. Nguyen DB, Wagner-Britz L, Maia S, Steffen P, Wagner C, Kaestner L, Bernhardt I (2011) Regulation of phosphatidylserine exposure in red blood cells. Cell Physiol Biochem 28(5):847-856. https ://doi.org/10.1159/000335798

39. Kebir D, József L, Pan W, Filep JG (2008) Myeloperoxidase delays neutrophil apoptosis through CD11b/CD18 integrins and prolongs inflammation. Circ Res 103(4):352-359. https://doi. org/10.1161/01.RES.0000326772.76822.7a 
40. Johansson MW, Patarroyo M, Oberg F, Siegbahn A, Nilsson K (1997) Myeloperoxidase mediates cell adhesion via the alpha M beta 2 integrin (Mac-1, CD11b/CD18). J Cell Sci 110(Pt9):1133-1139

41. Closse C, Dachary-Prigent J, Boisseau MR (1999) Phosphatidylserine-related adhesion of human erythrocytes to vascular endothelium. Br J Haematol 107:300-302. https://doi.org/10.104 6/j.1365-2141.199.01718.x

42. Grochmal A, Ferrero E, Milanesi L, Tomas S (2013) Modulation of in-membrane receptor clustering upon binding of multivalent ligands. J Am Chem Soc 135(27):10172-10177. https:// doi.org/10.1021/ja404428u

43. Jung H, Robison AD, Cremer PS (2009) Multivalent ligand-receptor binding on supported lipid bilayers. J Struct Biol 168(1):9094. https://doi.org/10.1016/j.jsb.2009.05.010

44. Nigg EA, Bron C, Girardet M, Cherry RJ (1980) Band 3-glycophorin A association in erythrocyte membrane demonstrated by combining protein diffusion measurements with antibodyinduced cross-linking. Biochemistry 19(9):1887-1893. https:// doi.org/10.1021/bi00550a024

45. Auffray I, Marfatia S, de Jong K, Lee G, Huang CH, Paszty C, Tanner MJ, Mohandas N, Chasis JA (2001) Glycophorin A dimerization and band 3 interaction during erythroid membrane biogenesis: in vivo studies in human glycophorin A transgenic mice. Blood 97(9):2872-2878. https://doi.org/10.1182/blood V97.9.2872

Publisher's Note Springer Nature remains neutral with regard to jurisdictional claims in published maps and institutional affiliations.

\begin{tabular}{|l|l|l|l|l|}
\hline Journal : Large 11010 & Article No: $\mathbf{3 6 5 4}$ & Pages : 12 & MS Code : 3654 & Dispatch : 15-11-2019 \\
\hline
\end{tabular}


Journal: $\quad \mathbf{1 1 0 1 0}$

Article: $\quad \mathbf{3 6 5 4}$

\section{Author Query Form}

\section{Please ensure you fill out your response to the queries raised below and return this form along} with your corrections

Dear Author

During the process of typesetting your article, the following queries have arisen. Please check your typeset proof carefully against the queries listed below and mark the necessary changes either directly on the proof/online grid or in the 'Author's response' area provided below

\begin{tabular}{|l|l|c|}
\hline Query & Details Required & Author's Response \\
\hline AQ1 & $\begin{array}{l}\text { Journal instruction requires a city and country for affiliations; however, these are } \\
\text { missing in affiliations [5, 6]. Please verify if the provided city and country are correct } \\
\text { and amend if necessary. }\end{array}$ & \\
\hline AQ2 & $\begin{array}{l}\text { Figures: figures }(3,4 a) \text { are poor in quality as its labels are not readable. Please supply a } \\
\text { new version of the said figure with legible labels preferably in .eps, .tiff or .jpeg format } \\
\text { with 600 dpi resolution. }\end{array}$ & \\
\hline
\end{tabular}

